\title{
Papers
}

\section{Reducing violence in severe mental illness: randomised controlled trial of intensive case management compared with standard care Topic: 84;161;170;298}

\author{
Elizabeth Walsh, Catherine Gilvarry, Chiara Samele, Kate Harvey, Catherine Manley, Peter Tyrer, \\ Francis Creed, Robin Murray, Thomas Fahy for the UK700 Group
}

\begin{abstract}
Objectives To establish whether intensive case management reduces violence in patients with psychosis in comparison with standard case management.

Design Randomised controlled trial with two year follow up.

Setting Four inner city community mental health services.

Participants 708 patients with established psychotic illness allocated at random to intervention (353) or control (355) group.

Intervention Intensive case management (caseload 10-15 per case manager) for two years compared with standard case management (30-35 per case manager). Main outcome measure Physical assault over two years measured by interviews with patients and case managers and examination of case notes.

Results No significant reduction in violence was found in the intensive case management group compared with the control group $(22.7 \%$ v $21.9 \%$, $\mathrm{P}=0.86$ ).

Conclusions Intensive case management does not reduce the prevalence of violence in psychotic patients in comparison with standard care.
\end{abstract}

\section{Introduction}

Serious acts of violence committed by people with mental illness are statistically rare events. ${ }^{1}$ Efforts of community services to prevent violence by the small subgroup at risk may be limited by the lack of effectiveness of standard treatment interventions, inadequate attention to clinical factors associated with violencefor example, drug misuse and poor engagement and treatment adherence by patients-and the difficulty of altering risk associated with impoverished and dangerous living environments. ${ }^{2}$ Fragmentation between services compounds the difficulties.

The care programme approach was introduced, partly to address this fragmentation, after several killings by people with severe mental illness were much reported in the media. ${ }^{4}$ The key elements are assessment of need and risk, development of a care plan, nomination of a responsible key worker, and regular review. Case management incorporates these principles, with the key worker providing direct care and also organising the delivery of a range of other services tailored to each patient's individual needs. Intensive case management emphasises small caseloads (10-15 patients per case manager), with increased intensity of contact.

Surprisingly, no study has specifically examined the effect on violence of increasing the intensity of treatment in the community. As part of the largest randomised controlled trial of intensive case management in patients with psychosis conducted to date, we assessed whether intensive case management reduced the prevalence of violence in comparison with standard case management.

\section{Methods}

\section{Study population}

The participants in the trial were recruited as part of the UK700 randomised controlled trial of the efficacy of intensive case management in patients with psychosis. The methods have been reported in detail elsewhere. ${ }^{5}$ Recruitment took place between February 1994 and April 1996 in four inner city mental health services-three in London (St George's Hospital, St Mary's Hospital, King's College Hospital) and one in Manchester (Manchester Royal Infirmary)-and occurred either at the point when patients were discharged from hospital or while they were receiving care in the community. Inclusion criteria were age between 18 and 65, a diagnosis of psychosis according to research diagnostic criteria, ${ }^{6}$ and at least two inpatient admissions for psychotic illness, with one in the previous two years. Patients with a primary diagnosis of substance misuse or organic brain damage were excluded. The trial was approved by the four local ethics committees.

\section{Intervention}

Intensive case management was compared with standard care for two years. The study was designed so that only one key variable (size of caseload) differed between the experimental and control groups. Intensive case managers had caseloads of 10-15 patients, whereas standard case managers had 30 or
Editorial by Steinert

Section of Forensic Mental Health, Guy's, King's and

St Thomas's School of Medicine,

Institute of

Psychiatry, London

SE5 8AF

Elizabeth Walsh

clinical lecturer

Thomas Fahy professor of forensic mental health

Division of

Psychological Medicine, Institute of Psychiatry

Catherine Gilvarry research psychologist Robin Murray professor of psychiatry

Department of Community Psychiatry,

St George's Hospital Medical School, London SE17 0RE

Chiara Samele research fellow Kate Harvey research psychologist

Academic Unit of Psychiatry, St Mary's Hospital Medical School, St Charles Hospital, London W10 6DZ

Catherine Manley research associate

Peter Tyrer professor of community psychiatry continued over

BMJ 2001;323:1-5 
University

Department of

Psychiatry,

Manchester Royal

Infirmary,

Manchester

M13 9WL

Francis Creed

professor of

psychological medicine

Correspondence to:

E Walsh

sppmemw@iop.kcl.

ac.uk more patients. Case managers were mostly community psychiatric nurses but could also be psychologists, occupational therapists, mental health support workers, or social workers. The level of training and skill was similar in the intensive and standard groups. ${ }^{5}$

We monitored activity of case managers throughout the trial and recorded five types of event: face to face contact with patient, contact by telephone $(>15$ minutes), contact with carer ( $>15$ minutes), coordination (contact with other professional agencies) $(>15$ minutes), and attempted (failed) face to face contact. For all face to face contacts, the primary focus of the event was categorised into 11 types, identified by a modified Delphi process and including housing, finance, medication, and criminal justice system. Staff were trained in and issued with guidelines on the use of event records and met frequently with the event record coordinator. The completeness of event records was verified by audits of case notes. ${ }^{7}$

\section{Assignment}

After giving written informed consent and being interviewed, patients were individually randomised to intensive case management or standard care. The randomisation list was drawn up using random numbers generated by computer. Randomisation was conducted by telephone or fax through an independent statistical centre and was stratified by centre, ethnic origin, and source of recruitment (at point of discharge or in the community). Outpatients were transferred to their case manager within four weeks, and inpatients were assigned when discharge was imminent.

\section{Outcomes and follow up}

Participants were interviewed by independent researchers at baseline and two years after randomisation. Researchers were senior trainee psychiatrists or psychology graduates who were totally independent of clinical care but, for safety purposes, were not always masked to treatment allocation. Researchers were asked to contact case managers before visiting patients at home. The primary outcome measure for the UK700 trial was number of days in hospital, and the results have been reported elsewhere. ${ }^{5}$ For the current study the outcome of interest was physical assault in the two years of the trial.

Three data sources were combined to produce a binary outcome measure for each patient. A positive score on any of these sources indicated a positive score for assault. The frequency or seriousness of assault was not recorded. Firstly, as part of the World Health Organization's life chart process, ${ }^{8}$ patients were asked whether they had physically assaulted anyone in the two year period. Where an interview with a participant was not possible, an attempt was made to complete the record with information from a carer. Secondly, case managers were interviewed in person or by telephone and asked about any physical assault committed by their patients. Thirdly, case notes at all sites were individually inspected for evidence of physical assault.

Possible sociodemographic $(n=12)$ and clinical $(\mathrm{n}=13)$ risk factors for violence, chosen a priori on the basis of previous research, were estimated at baseline interview by using a battery of instruments. ${ }^{8-11}$ Criminal records, including convictions for violence, were obtained from the Home Office for all participants. As the date of conviction rather than the

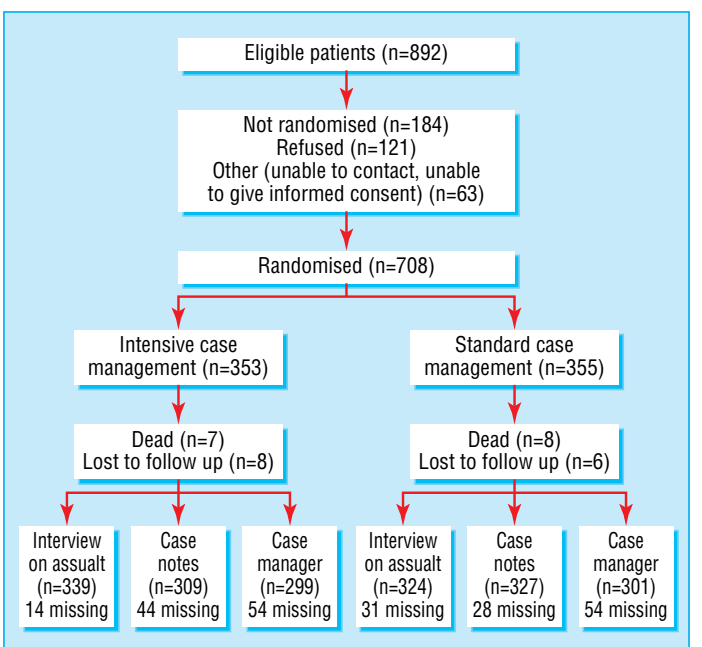

Flowchart of trial

date of offence is recorded in the index of offenders, it was not possible to include violent convictions during the follow up period in the main outcome measure.

\section{Power calculation and statistical analysis}

The trial with 350 patients randomised to each group would be able to detect a $20 \%$ reduction in total violence in the intensive case management group as statistically significant at the $5 \%$ level with a high probability (power $>80 \%$ ). We estimated the proportion of participants who committed assault during the trial and compared treatment groups by using the $\chi^{2}$ test. Analyses were conducted with Stata 5 (Stata Corporation, College Station, TX). We used logistic regression to perform univariate and multivariate analyses to identify predictors of assault during the two years of the trial.

\section{Results}

\section{Recruitment}

Eighty per cent of patients approached agreed to participate (figure). In all, 708 patients were recruited, 353 $(49.8 \%)$ in the intervention group and $355(50.2 \%)$ in the control group. Comparisons between those who entered and those who did not revealed no significant differences in terms of demographic and clinical characteristics, apart from length of illness. Patients who entered the trial had been ill for longer (median duration 120 months $v 96$ months; $\mathrm{U}=51899.0 ; \mathrm{P}=0.04$ ). Details of the sociodemographic and clinical features of the participants in the UK700 trial have been described in detail elsewhere. ${ }^{5}$

\section{Intervention}

Patients in the intensive case management group received more than twice as much care as control patients, with a mean of 4.41 events per 30 days compared with 1.94 in the standard arm. The mean duration of face to face contacts was 40.6 (SD 0.3) minutes in the intensive management group and 37.4 (24.8) minutes in the standard group. Patients managed intensively had significantly more of each type of event apart from failed contacts and had significantly more contacts in nine of the 11 focus areas. Specifically, they received significantly more contacts related to the criminal justice system, engage- 


\begin{tabular}{|c|c|}
\hline Factor & $\begin{array}{l}\text { Risk ratio }(95 \% \mathrm{Cl}) \text { adjusted } \\
\text { for all other variables in table }\end{array}$ \\
\hline \multicolumn{2}{|l|}{ Age: } \\
\hline 19-39 years & $1.53(1.12 \text { to } 2.02)^{\star}$ \\
\hline $40-64$ years & 1 \\
\hline \multicolumn{2}{|l|}{ Special education: } \\
\hline No & 1 \\
\hline Yes & $1.61(1.08 \text { to } 2.20)^{*}$ \\
\hline \multicolumn{2}{|l|}{ Victimised in past year: } \\
\hline No & 1 \\
\hline Yes & $1.50(1.08 \text { to } 2.02)^{\star}$ \\
\hline \multicolumn{2}{|l|}{ Drug use/misuse: } \\
\hline None & 1 \\
\hline One or more & $1.49(1.09 \text { to } 1.95)^{\star \star}$ \\
\hline \multicolumn{2}{|l|}{ Assault (past 2 years): } \\
\hline No & 1 \\
\hline Yes & $2.04(1.54 \text { to } 2.56)^{\star \star \star}$ \\
\hline \multicolumn{2}{|l|}{ History of conviction for violence: } \\
\hline No & 1 \\
\hline Yes & $1.44(1.02 \text { to } 2.61)^{*}$ \\
\hline \multicolumn{2}{|l|}{ Randomisation: } \\
\hline Standard case management & 1 \\
\hline Intensive case management & 1.08 (0.78 to 1.44$)$ \\
\hline
\end{tabular}

ment, finance, and medication-all variables that might influence the prevalence of violent behaviour.

\section{Prevalence of violence}

Information on assault was available for all patients from at least one data source. During the two years of the trial $158(22 \%)$ participants physically assaulted another person. Violent behaviour was reported by $104(66 \%)$ of the 158 patients. Combining data from case notes and interviews with patients resulted in 143 $(91 \%)$ of the 158 patients being reported as having been violent. The addition of interviews with case manager to these measures led to a further $15(9 \%)$ patients being included. Only $16(10 \%)$ patients were reported as violent by all three data sources. Eighty $(23 \%)$ of the intervention group and $78(22 \%)$ of the control group committed assault, representing no significant difference $\left(\chi^{2}=0.048, \mathrm{P}=0.86\right)$. The relative risk for committing assault in the intensive group compared with the standard group was 1.03 (95\% confidence interval 0.72 to 1.46 ). Identified risk factors for violence included previous violence, younger age, drug misuse, victimisation, and learning difficulties (table). After adjustment for these factors, the difference in prevalence of violence between the groups remained non-significant.

\section{Discussion}

In the largest randomised trial to date comparing intensive case management with standard care in psychosis, no significant reduction in violence was found. Risk factors for violence included previous violence, drug misuse, younger age, and victimisation, confirming the results of previous studies in psychotic patients. ${ }^{12}{ }^{13}$ Violence was also associated with a history of learning difficulties, a factor previously identified in non-psychotic populations. ${ }^{14}$

Strengths and weaknesses of the study

Different methods for measuring violence can produce very different prevalences. The recent use of multiple combined measures, as in this study, has highlighted the limitations of most previous studies, which relied on a single source. One study that specifically compared the yield of violence when different sources were used revealed a dramatically different picture of violence by patients depending on the source of information used. ${ }^{15}$ Our results support the observation that self report methods consistently produce a higher frequency of violence than use of other records. ${ }^{16}$ In a small proportion of cases the WHO life chart was completed from sources other than the patient, so the $94 \%$ response rate is a slight overestimate.

The optimal prevalence estimate would have been detected with $100 \%$ follow up on all data sources. Although we did not achieve this, we did obtain information on all participants from at least one source. One possible source of bias in this study is that intensive case managers may have detected more violent acts and that standard case managers may have under-reported violence. This could conceal an actual reduction in violence in the intensive group. This is unlikely to be the case as the interviews with case managers added only 15 participants who had not been identified by self report or review of case notes. These cases were evenly distributed between the groups. Additionally, we included only actual assaults, and not threats, in our definition so it is likely that most of these more serious incidents will have been detected irrespective of treatment allocation.

Possible bias arising from interviewers not always being blind to treatment group will have been minimised by the use of multiple data sources. The use of validated questionnaires and continual data monitoring at each centre and centrally will have maximised the robustness of the data. Participants were recruited from inner city locations, and results may not be generalisable to other settings. The multicentre design with over 700 patients should, however, increase the external validity.

\section{Prevalence of violent behaviour}

The finding that $22 \%$ of patients committed assault over the two year period is of concern but concurs with previous work. Studies indicate that between $10 \%$ and $40 \%$ of patients commit assault before admission to hospital, and the MacArthur risk assessment study found that $27.5 \%$ of discharged psychiatric patients committed at least one violent act within a year of discharge. ${ }^{17}{ }^{18}$ Our study includes violence by both inpatients and outpatients.

Although intensively case managed patients received more face to face contacts with their case managers and more attention dedicated to medication, engagement, daily living skills, housing, and the criminal justice system, we found no evidence that intensive case management reduced the prevalence of violent behaviour over two years. This finding is not challenged by any of the published trials in this field. There have been at least seven randomised controlled trials examining the efficacy of assertive community treatment-the form of intensive case management favoured in the United States-that have included time in jail or legal contacts as an outcome measure. ${ }^{19-25}$ None has examined violence specifically, and only two of the seven reported reductions in time in jail..$^{21}{ }^{22}$ Differences in the organisation of services, in particular 
the absence of coordinated care in American standard practice, limit the generalisability of these findings to the British setting.

A randomised trial of the management of care by social services conducted in homeless people with severe mental illness in Oxford found a significant reduction in deviant behaviour in the care management group at 14 months' follow up in comparison with care as usual. ${ }^{26}$ Although this result was encouraging, the study did not examine violent behaviour specifically, the intensity of the intervention was decided by the individual's care manager, and the level of care received by the control group was unclear. We must therefore conclude that intensive case management, or indeed assertive community treatment, has shown no efficacy in reducing violent behaviour in severely mentally ill patients.

\section{Implications of the study}

It remains unclear why intensive community treatment has such a negligible effect on illegal behaviours. In those studies examining time in jail as a secondary outcome the base rate of time spent in jail may have been too low to detect a change in some samples. Alternatively, assertive community treatment and intensive case management have been designed as vehicles for providing clinical services and reducing reliance on inpatient facilities, and these interventions may need considerable modification to address the different needs of patients who are prone to engage in violent or illegal behaviour. Specific interventions to improve compliance with or uptake of treatment for substance misuse are probably important. More controlled research on this question is needed.

Despite the lack of empirical studies on the effect of increasing the intensity of treatment in the community on violence in general psychiatric or forensic populations, research in the United States is now focusing on the effect of combining community treatment with legally enforceable interventions to reduce violence. A recent study, with some important limitations in its methods, found that outpatient commitment (enforced community treatment) for longer than six months combined with regular services resulted in a significant reduction in community violence in severely mentally ill patients at risk of violence. Neither outpatient commitment nor regular services alone was effective. ${ }^{27}$ Similar legislation for compulsory community treatment in England and Wales has recently been proposed in a government white paper. ${ }^{28}$ Future research may have the challenging task of evaluating the effectiveness of combining specific clinical interventions within or without a protective legal framework.

The UK700 Group is a collaborative study team involving four clinical centres. Manchester: Tom Butler, Francis Creed, Janelle Fraser, Peter Huxley, Nicholas Tarrier, Theresa Tattan. King's/Maudsley, London: Tom Fahy, Karyna Gilvarry, Kwame McKenzie, Robin Murray, Jim van Os, Elizabeth Walsh. St Mary's/St Charles' Hospitals, London: John Green, Anna Higgitt, Elizabeth van Horn, Donal Leddy, Catherine Manley, Patricia Thornton, Peter Tyrer. St George's Hospital, London: Rob Bale, Tom Burns, Matthew Fiander, Kate Harvey, Andy Kent, Chiara Samele. York (health economics): Sarah Byford, David Torgerson, Ken Wright. London School of Hygiene and Tropical Medicine (statistical centre): Simon Thompson, Ian White.
What is already known on this topic

Psychosis and violence are known to be associated

Community psychiatric interventions aimed at reducing the risk of violence have not been evaluated

\section{What this study adds}

Increasing the intensity of contact between patients and case managers does not reduce the prevalence of violent behaviour in patients with psychosis

Younger age, learning difficulties, and a history of violence, drug misuse, and victimisation predict violent behaviour in psychotic patients

Contributors: EW contributed to the idea for the study, collected data at the four clinical sites, analysed the data, and drafted the manuscript. CG, CS, KH, and CM collected data and helped to draft and revise the manuscript. PT, FC, and RM advised on the study design and execution and critically revised the text for intellectual content. TF conceived the idea for the study, coordinated the research, and revised the manuscript. EW and TF are the guarantors.

Funding: EW was funded by a Wellcome Training Fellowship. The UK700 trial was funded by grants from the Department of Health and NHS research and development programme.

Competing interests: None declared.

1 Monahan J. Mental disorder and violent behaviour: perceptions and evidence. Am Psychol 1992;47:511-21.

2 Swartz MS, Swanson JW, Hiday VA, Borum R, Wagner HR, Burns BJ. VioSwartz MS, Swanson JW, Hiday VA, Borum R, Wagner HR, Burns BJ. Vioadherence to medication. Am J Psychiatry 1998;155:226-31.

3 Silver E, Mulvey EP, Monahan J. Assessing violence risk among discharged psychiatric patients: toward an ecological approach. Law Hum Behav 1999;23:237-55.

4 Department of Health. The care programme approach for people with a mental illness referred to the specialist psychiatric services. London: Department of Health, 1990.

5 UK700 Group. Intensive versus standard case management for severe psychotic illness: a randomised trial. Lancet 1999;353:2185-9.

6 Spitzer R, Endicott J, Robins E. Research diagnostic criteria: rationale and reliability. Arch Gen Psychiatry 1978;35:773-82.

7 Burns T, Fiander M, Kent A, Ukoumunne OC, Byford S, Fahy T, et al. Effects of case-load size on the process of care of patients with severe psychotic illness. Br J Psychiatry 2000;177:427-33.

8 World Health Organization. The life chart. Geneva: WHO, 1992.

9 Asberg M, Montgomery SA, Perris C. The CPRS-development and applications of a psychiatric rating scale. Acta Psychiatr Scand 1978;271(suppl):5-27.

10 Andreason NC. Modified scale for the assessment of negative symptoms. Iowa City: University of Iowa, 1984.

11 Phelan M, Slade M, Thornicroft G, Dunn G, Holloway F, Wykes T, et al. The Camberwell assessment of need: the validity and reliability of an instrument to assess the needs of people with severe mental illness. $\mathrm{BrJ}$ instrument to assess the ne.
Psychiatry 1995;167:589-95.

12 Buchanan A. The investigation of acting on delusions as a tool for risk assessment in the mentally disordered. Br J Psychiatry 1997;170(suppl 32):12-6.

13 Swanson JW, Borum R, Swartz M, Hiday V. Violent behaviour preceding hospitalisation among persons with severe mental illness. Law Hum Behav 1999:23:185-204.

14 Hodgins S. Mental disorder, intellectual deficiency, and crime. Evidence from a birth cohort. Arch Gen Psychiatry 1992;49:476-83.

15 Mulvey EP, Shaw E, Lidz CW. Why use multiple sources in research on patient violence in the community? Crim Behav Mental Health 1994;4:253-8.

16 Elliott D, Huizinga D, Morse B. Self-reported violent offending: a descriptive analysis of juvenile violent offenders and their offending careers. Interpersonal Viol 1986;1:472-513.

17 Steadman H, Mulvey EP, Monahan J, Robbins PC, Applebaum PS, Grisso T, et al. Violence by people discharged from acute psychiatric inpatient facilities and by others in the same neighborhoods. Arch Gen Psychiatry 1998;55:1-9.

18 Monahan J. Clinical and actuarial predictions of violence. In: Faigman D, Kaye D, Saks M, Sanders J, eds. Modern scientific evidence: the law and science of expert testimony. Vol 1. St Paul, MN: West Publishing Company, 1997:300-18. 
19 Chandler D, Meisel J, McGowen M, Mintz J, Madison K. Client outcomes in two model capitated integrated service agencies. Psychiatr Serv $1996 ; 47: 175-80$.

20 Bond GR, Miller LD, Krumwied RD, Ward RS. Assertive case management in three CMHCs: a controlled study. Hosp Community Psychiatry 1988;39:411-8.

21 Bond GR, Witheridge TF, Dincin J, Wasmer D, Webb J, De Graaf-Kaser R. Assertive community treatment for frequent users of psychiatric hospitals in a large city: a controlled study. Am J Community Psychol 1990;18:865-91.

22 Lehman AF, Dixon LB, Kernan E, DeForge B. A randomised trial of assertive community treatment for homeless persons with severe menta illness. Arch Gen Psychiatry 1997;54:1038-43.

23 Solomon P, Draine J. The efficacy of a consumer case management team: 2-year outcomes of a randomised trial. $J$ Mental Health Admin $1995 ; 22: 126-34$
24 Stein LI, Test MA. Alternative to mental hospital treatment: 1. Conceptual model, treatment program, and clinical evaluation. Arch Gen Psychiatry 1980;37:392-7.

25 Test MA. Training in community living. In: Liberman RP, ed. Handbook of psychiatric rehabilitation. New York: Macmillan, 1992.

26 Marshall M, Lockwood A, Gath D. Social services case-management for long term mental disorders: a randomised controlled trial. Lancet 1995;345:409-12.

27 Swanson JW, Swartz MS, Borum R, Hiday VA, Wagner HR, Burns BJ Involuntary out-patient commitment and reduction of violent behaviou in persons with severe mental illness. Br J Psychiatry 2000;176:324-31.

28 Secretary of State for Health. Reforming the Mental Health Act. London: Stationery Office, 2000.

(Accepted 23 July 2001) 